\title{
Effects of Cold Stimulation Induced Pain on Cardiopulmonary Parameters: A Gender Based Study Jha RK, ${ }^{1}$ Amatya $\mathrm{S}^{2}$
}

\author{
Corresponding Author \\ Reena Kumari Jha \\ Department of Physiology, \\ Kathmandu University School of Medical Sciences, \\ Dhulikhel, Kavre, Nepal. \\ E-mail: reena2017dec@gmail.com
}

\section{Citation}

Jha RK, Amatya S. Effects of Cold Stimulation Induced Pain on Cardiopulmonary Parameters: A Gender Based Study. Kathmandu Univ Med J. 2020;69(1): 15-8.

\begin{abstract}
Background

Cold pressor induced pain elicits sympathetic responses which can be monitored by measuring blood pressure, heart rate and respiratory rate after exposure to the cold stress.
\end{abstract}

\section{Objective}

This study was done to evaluate gender difference in acute pain induced by cold pressor test on blood pressure, heart rate and respiratory rate of healthy individuals.

\section{Method}

Our study was cross sectional study with the sample size of 40 including 20 male and 20 female undergraduates. Acute pain was induced by immersion of hand in cold water at $4{ }^{\circ} \mathrm{C}$. Changes in blood pressure, heart rate and respiratory rate were recorded by the digital sphygmomanometer and AD Instruments (Model: ML856, Serial: T26-4025) and analysis was done by Lab Chart 7 Pro v 7.3.3 respectively. Acute pain parameter like pain threshold was also recorded. Statistical analysis was done by using Paired " $\mathrm{t}$ " test and non-parametric test.

\section{Result}

The present study enrolled 40 participants, aged between $18-24$ years, and body mass index from $15.78-36.06 \mathrm{~kg} / \mathrm{m}^{2}$. The respiratory rate was increased in both males $(17.30 \pm 3.19$ to $19.0 \pm 3.21, P=0.01)$ and females $(18.60 \pm 1.98$ to $19.90 \pm 2.82$, $\mathrm{P}=0.01$ ) however significant increase in heart rate was only found in females (77.80 \pm 8.07 to $80.70 \pm 7.80, P=0.03$ ) after cold pressor test. The systolic as well as diastolic blood pressure did not increase significantly after cold pressor test. The pain thresholds ranged from 25.2 to 105.8 seconds (61.60 \pm 23.26 , male Vs. $52.69 \pm 18.49$, female, $p=0.188$ ).

\section{Conclusion}

Our findings point towards autonomic adjustments suggesting more of sympathetic over activity immediately after cold pressor test.

\section{KEY WORDS}

Blood pressure, Cold pressor test, Heart rate, Respiratory rate 


\section{INTRODUCTION}

Cold Pressor test was first introduced by Hines and Brown in 1932, to determine vascular reactivity. ${ }^{1}$ Immersion of limb in cold water has long been known to induce acute pain. ${ }^{2}$ The International Association for the Study of Pain (IASP) defines pain as unpleasant sensory and emotional experiences, associated with actual or potential tissue damage. ${ }^{3}$ After being stimulated by acute pain, the sympathetic system increases heart rate, blood pressure, skin conductance, pupil size and respiratory rate; nevertheless, heart rate and blood pressure usually return to normal levels within a very short period of time after withdrawal of the stressor. ${ }^{1,4-8}$

In healthy subjects, stress exerted through the cold pressor test (CPT) stimulated sympathetic system and produced an acceleration of the blood pressure both systolic and diastolic. ${ }^{9-12}$ The heart rate (HR) response to this test is less well defined, with a high inter-individual variability and not homogenous for the entire CPT period. ${ }^{9,13,14}$ Two major pattern either increased or unchanged heart rate was observed in response to cold pressor test. ${ }^{11,12,14,15}$ During the cold induced acute pain, both rate and depth of respiration was increased. The increase in rate and tidal volume indicates that cold induced pain has a stimulatory effect on ventilation. ${ }^{7}$

Cold pressor test has been used for the diagnosis of cardiovascular reactivity in normotensive and hypertensive subjects and the responses to CPT may help to identify normotensive candidates at future risk of suffering from hypertensive disease. ${ }^{9}$ Thus the aim of this study was to estimate the changes in the cardio-pulmonary parameters in response to acute pain produced by cold pressor test in healthy subjects.

\section{METHODS}

A cross sectional study was carried among forty healthy undergraduates, twenty males and twenty females, aged between 18 to 24 years, at Kathmandu University School of Medical sciences (KUSMS) Chaukot, Kavre. Recruitment was started from April 2016 to September 2016 after taking approval from institutional review committee of Kathmandu University School of Medical Sciences/ Dhulikhel Hospital (IRC-KUSMS). Sample was collected randomly from the population. Subjects suffering with cardiorespiratory disease and autonomic dysfunction were excluded from the study.

Each subject was called individually to departmental research laboratory, asked to sit on the chair comfortably and relax for five minutes. Meantime, respiratory belt was wrapped around the chest and then the transducer was connected to an ADInstruments (Model:ML856, Serial:T26-4025); cuff of the digital sphygmomanometer was tied on the middle of the non-dominant arm. Acute pain was induced by cold pressor test (immersion of dominant hand upto wrist in cold water at $4^{\circ} \mathrm{C}$ until the subject perceived the sensation of pain) and the heart rate, blood pressure, respiratory rate were recorded before and immediately after the pain was felt. Acute pain parameter like pain threshold was also recorded in seconds. Comparison was made between values recorded before and after cold induced pain.

The data thus obtained were exported to Microsoft Excel and then to Statistical Package for the Social Sciences (SPSS), version 16 for further analysis. The Results were analyzed by student's test and non-parametric test. In all tests performed, $p$ value $<0.05$ was considered to be significant.

\section{RESULTS}

Out of 40 undergraduates, $50 \%$ were males and $50 \%$ were females. The age range of participants were $18-24$ years. We observed that the respiratory rate was increased significantly with CPT in both males and females however significant increase in heart rate was only found in females.

In males, the heart rate, systolic blood pressure and diastolic blood pressure were increased after cold pressor test but not significant. Insignificant increase in systolic as well as diastolic blood pressor was also found in females. While comparing between male and female, difference in heart rate was more in female than male and difference in systolic blood pressure, diastolic blood pressure, respiratory rate were more in male than female but not significant.

Table 1. Anthropometric variables of male and female subjects.

\begin{tabular}{|llll|}
\hline Variables & $\begin{array}{l}\text { Male } \\
\text { Mean } \pm \text { SD }\end{array}$ & $\begin{array}{l}\text { Female } \\
\text { Mean } \pm \text { SD }\end{array}$ & P value \\
\hline Age (years) & $21.45 \pm 1.66$ & $20.0 \pm 1.41$ & 0.005 \\
\hline BMI $\left(\mathrm{kg} / \mathrm{m}^{2}\right)$ & $22.39 \pm 4.21$ & $21.19 \pm 4.09$ & 0.368 \\
\hline Pain Threshold (Seconds) & $61.60 \pm 23.26$ & $52.69 \pm 18.49$ & 0.188 \\
\hline
\end{tabular}

The pain thresholds in the subjects ranged from 25.2 to 105.8 seconds with mean pain thresholds not significantly different between males and females as shown in Table 1.

Table 2. Effect of gender on cardiopulmonary variables before and after cold pressor test

\begin{tabular}{|lllll|}
\hline Variables & Gender & $\begin{array}{l}\text { Before CPT } \\
\text { Mean } \pm \text { SD }\end{array}$ & $\begin{array}{l}\text { After CPT } \\
\text { Mean } \pm \text { SD }\end{array}$ & $\begin{array}{l}\text { P } \\
\text { value }\end{array}$ \\
\hline Heart Rate $(\mathrm{bpm})$ & Male & $76.35 \pm 8.21$ & $77.70 \pm 6.88$ & 0.36 \\
\cline { 2 - 5 } & Female & $77.80 \pm 8.07$ & $80.70 \pm 7.80$ & 0.03 \\
\hline $\begin{array}{l}\text { Systolic Blood } \\
\text { Pressure (mmHg) }\end{array}$ & Male & $121.40 \pm 9.01$ & $123.95 \pm 11.22$ & 0.44 \\
\hline $\begin{array}{l}\text { Diastolic Blood } \\
\text { Pressure (mmHg) }\end{array}$ & Male & $74.84 \pm 6.59$ & $76.50 \pm 6.59$ & 0.23 \\
\hline $\begin{array}{l}\text { Respiratory Rate } \\
\text { (cycles/min) }\end{array}$ & Male & $17.30 \pm 3.19$ & $19.0 \pm 3.21$ & 0.01 \\
\hline & Female & $18.60 \pm 1.98$ & $19.90 \pm 2.82$ & 0.01 \\
\hline
\end{tabular}


The effect of acute pain induced by cold pressor test on heart rate, respiratory rate, systolic and diastolic blood pressure in male and female subjects are shown in Table 2.

Table 3 shows difference between male and female in term of variation in heart rate, systolic blood pressure, diastolic blood pressure and respiratory rate.

Table 3. Comparison of difference in Cardiopulmonary Parameters in Male and Female Subjects

\begin{tabular}{|llll|} 
Variables & $\begin{array}{l}\text { Male } \\
\text { Median } \pm \text { IQR }\end{array}$ & $\begin{array}{l}\text { Female } \\
\text { Median } \pm \text { IQR }\end{array}$ & P value \\
\hline Difference in HR & $1.0 \pm 5.5$ & $2.5 \pm 4.75$ & $>0.05$ \\
\hline Difference in SBP & $3.0 \pm 12.5$ & $2.5 \pm 9.75$ & $>0.05$ \\
\hline Difference in DBP & $2.5 \pm 9.25$ & $2.0 \pm 8.0$ & $>0.05$ \\
\hline Difference in RR & $2.5 \pm 4.75$ & $2.0 \pm 1.75$ & $>0.05$ \\
\hline
\end{tabular}

\section{DISCUSSION}

In this study, pain threshold during cold pressor test was found to be higher in males compared to females, but this difference was not significant and was likely due to small sample size (20 males and 20 females). Similar result was found by Nie et al. ${ }^{16}$ However several researchers found that males showed significant higher pain thresholds than females. ${ }^{17-20}$ Mechanisms posited to account for these differences remain unclear. It has been suggested that several factors such as sociocultural factors, genetic factor, body size, anxiety and hormonal influences may play role. ${ }^{21}$ It is claimed that the gender differences in pain sensitivity is due in part to the effect of gonadal hormones. There are two main gonadal hormones in female, estrogen and progesterone and their concentration in plasma changes during menstrual cycle. Physiologically, the menstrual cycle is divided into three phases: the follicular phase, the ovulatory phase, and the luteal phase. The follicular phase is characterized by low levels of estrogen and progesterone and high levels of the follicular stimulating hormone (FSH). The ovulatory phase is characterized by a peak concentration of estrogen and the peak of luteinizing hormone (LH). The luteal phase is characterized by high levels of progesterone and low levels of FSH, LH, and estrogen. ${ }^{3}$ Some researchers found increased pain sensitivity during luteal phase relative to follicular phase of menstrual cycle and those high serum progesterone concentrations corresponds to that. ${ }^{20-24}$ Progesterone increases excitability of spinal neurons by altering the permeability of ion channels. Thus it decreases pain threshold and increases pain sensitivity in the females. It has also been shown that luteinizing hormone (LH) surge which occurs two days prior to ovulation in females decreases analgesic response in females by desensitizing brain opiate receptors. ${ }^{20}$ This is probably because the $\mu$ receptors in healthy brain are activated differently in response to pain in both males and females. ${ }^{17}$ It has also been proved that testosterone has a masking effect on the perception of pain. ${ }^{18}$ Endorphins, the endogenous analgesic substances that cause activation of analgesic system in the body, are released more in male. Thus higher quantity of endorphin in the males greatly increases their pain threshold. ${ }^{19}$

In the present study, Cardiopulmonary parameters such as heart rate, blood pressure, respiratory rate were tend to increased immediately after cold pressor test however $H R$ was significantly increased in females and RR was increased in both males and females after the experiment. In healthy human subjects, cold pressor triggers an increase in heart rate, systolic as well as diastolic blood pressure and respiratory rate. ${ }^{6,25}$ Immersion of a hand in cold water acts as a pain stimulus and causes massive stimulation of the sympathetic nervous system and release of norepinephrine. This sympathetic stimulation triggers arteriolar constriction, increased $H R$, and increased cardiac contractility. Both increased cardiac contractility as well as heart rate increases cardiac output. Increased cardiac output increases systolic blood pressure and arteriolar constriction increases diastolic blood pressure respectively. ${ }^{25}$ Mourot et al. observed either increased or unchanged heart rate response to pain induced by the cold stimulus. ${ }^{9}$ Thus they hypothesized that heart rate response could be associated with increase of baroreceptors stimulated vagal activity concomitant to the persistent sympathetic involvement.

Pain is a form of stress induced by CPT may cause either respiratory stimulation or inhibition, depending on its character, origin (visceral or somatic) and intensity. Nociceptive afferents can reflexly stimulate the respiratory centers. This stimulation of respiration could be secondary to the excitatory inputs of the higher centers to cardiorespiratory centers in the lower brainstem. ${ }^{7}$ There are studies showing that blockade of pain during CPT did not produce the pressor response indicating that it is the sensation of pain which is responsible for the type of cardiorespiratory response observed. ${ }^{26}$

Our study recorded the cardiopulmonary parameters before and immediately after cold pressor test applied. We did not record blood pressure, heart rate, and respiratory rate during the intervention (CPT). Sample size was also smaller. In future the author would like to recommend evaluating above mentioned parameters during the intervention with larger sample size. Females participating in this study were not asked about their menstrual history. In future that should also be kept in mind.

\section{CONCLUSION}

Our findings pointed towards autonomic adjustments suggesting stress such as pain induced through cold pressor test stimulates sympathetic nervous system. 


\section{ACKNOWLEDGEMENT}

The authors wish to thank the subjects for their time and cooperation. Moreover, sincere thanks to our late
Professor Bhupindra Kumar Kapoor for his continuous encouragement and support.

\section{REFERENCES}

1. Hines EA, Brown GE. Cold pressor test for measuring the reactivity of blood pressure. American Heart J. 1936;11:1-9.

2. Ponser J, Telekes A, Crowley D, Philipson R, Peck AW. Effects of an Opiate ion cold-induced pain and the CNS in Healthy Volunteers. Pain. $1985 ; 23: 73-82$

3. Barrett KE, Ganong WF. Ganong's review of medical physiology. McGraw-Hill Medical: New York. 2010:165

4. Wolf S, Hardy JD. Studies on Pain: Observations on pain due to local cooling and on factors involved in the cold pressor effect. J Clin. Invest. 1994; 20:521-33.

5. Dudley DL, Masuda M, Martin CJ, Holmes TH. Psycho physiological studies of experimentally induced action oriented behaviour. J Psychosom Res. 1965; 9:209-21.

6. Sternbach RA. Pain: psychophysiological analysis. New York, Academic Press 1968

7. Tandon OP, Himani A, Singh S. Pulmonary responses during cold induced acute pain. Indian J Physio Pharmacol. 1997; 41(1)16-22.

8. LeBlanc J, Dulac S, Côté J, Girard B. Autonomic nervous system and adaptation to cold in man. J Appl Physiol. 1975; 39:181-6.

9. Mourot L, Bouhaddi M, Regnardi J. Effects of the Cold Pressor Test on Cardiac Autonomic Control in Normal Subjects. Physiol. Res. 2009;58:83-91.

10. Victor RG, Leimbach WN, Seals DR, Wallin BG, Mark AL: Effects of the cold pressor test on muscle sympathetic nerve activity in humans. Hypertension. 1987; 9: 429-36.

11. Sendowski I, Savourey G, Launay JC, Besnard Y, Cottet-emard JM, Pequignot JM et.al. Sympathetic stimulation induced by hand cooling alters cold-induced vasodilatation in humans. Eur J Appl Physiol. 2000; 81: 303-9.

12. Cui J, Wilson TE, Crandall CG: Baroreflex modulation of muscle sympathetic nerve activity during cold pressor test in humans. Am J Physiol. 2002; 282: H1717-H1723.

13. Glenn D, Ditto B. Vagal tone biofeedback: respiratory and nonrespiratory mediated modulations of vagal tone challenged by cold pressor test. MacGill J Med. 2004; 7.

14. Dishman RK, Nakamura Y, Jackson EM, Ray CA. Blood pressure and muscle sympathetic nerve activity during cold pressor stress: fitness and gender. Psychophysiology. 2003;(40): 370-80.
15. Jauregui-renaud K, Hermosillo AG, Marquez MF, Ramos-Aguilar F, Hernandezoribar M, Cardenas M. Repeatability of heart rate variability during simple cardiovascular reflex tests on healthy subjects. Arch Med Res. 2001;32: 21-6.

16. Nie $H$, Arendt-Nielsen L, Andersen H, Graven-Nielsen T. Temporal summation of pain evoked by mechanical stimulation in deep and superficial tissue. J Pain. 2005;6(6):348-5.

17. Hallin SW. Sex differences in pain perception. Gender Medicine 2005;2(3):137- 45.

18. Pednedkar J, Mulgaonkar V. Role of testosterone on pain threshold in rats. Indian J Physiol Pharmacol. 1995;39:423-4.

19. Crafts RA. $\mu$ and kappa agonist generally produce greater analgesia in male rats. Brain Research. 1998 ; 809:137- 40.

20. Alberto C T. Changes in nociceptive flexion reflex threshold across the menstrual cycle in healthy women. Psychosomatic Medicine. 2002;64:621-6

21. Riley $\mathrm{JL} 3^{\text {rd }}$, Robinson ME, Wise EA, Myers CD, Fillingim RB. Sex differences in the perception of noxious experimental stimuli: $A$ meta-analysis. Pain. 1998;74(2-3):181-7.

22. Hellstrom B, Lundberg U. Pain perception to cold pressor test during the menstrual cycle in relation to estrogen levels and comparison with males. Intregative physiol and Behavio Sci. 2000;35:130-9.

23. Stening K, Eriksson O, Wahren L, Berg G, Hammar M, Blomqvist A. Pain sensations to the cold pressor test in normally menstruating women: comparison with men and relation to menstrual phase and serum sex steroid levels. Am J Physiol Regul Integr Comp Physiol. 2007;293(4):1711-6.

24. Chesterton LS, Barlos P. Gender differences in pressure pain threshold in healthy humans. Pain. 2003;101:259-66.

25. Von Baeyer $\mathrm{CL}$, Piira T, Chambers CT, Trapanotto $\mathrm{M}$, Zeltzer LK Guidelines for the cold pressor task as an experimental pain stimulus for use with children. J Pain. 2005; 6(4): 218-27

26. Monahan KD, Feehan RP, Sinoway LI, Gao Z. Contribution of sympathetic activation to coronary vasodilatation during the cold pressor test in healthy men: effect of ageing. J. Physiol. 2013; 591:2937-47. 